\title{
Autonomous Development of Professional Interpreting Trainers from the Perspective of Postmethod
}

\author{
Wang Honglin \\ Sichuan University/ Zhejiang Wanli University
}

\begin{abstract}
Interpreting teachers are the guarantee of the quality of interpreting education in the professionalization era,and we should pay attention to their professional development. Although much progress has been made in TOT (training of trainers), autonomous development of interpreting trainers have not drawn sufficient attention. By referring to the philosophy of postmethod, the study aims to explore the autonomous development mode of interpreting trainers, which covers the ideology of interpreting teachers' lifelong development, interpreting competence framework and evaluation model. Through seeking a autonomous development mode for interpreting teachers, it is conducive to enhancing their professional development and pushing forward the reform of interpreting trainers' education.
\end{abstract}

Keywords-Professionalized interpreting education; TOT; postmethod; Autonomous development

\section{INTRODUCTION}

With the professionalization of the translation industry, practitioners need to have professional qualifications, complying with professional ethics, understanding professional characteristics, and possessing professional competence and qualifications, therefore translators' associations must formulate professional standards and rules, establish access mechanisms and carry out vocational training (Mu Lei, 2012). TOT, which is training of trainers, conducted by Translators Association of China in the past 20 years, has contributed a lot to the translators' development in China. However, some studies have pointed out that: the official training has in some way enhanced translators' professional development, however, with regards to the great quantity of translation teachers all over China, problems still exist (Hua Liang, 2016).

As a key link in the implementation of interpreting education, interpreting trainers play a crucial role and are the guarantee of professional interpreting education. However, the current shortage of professionalized interpreters has become an indisputable fact. It is also found out that during the decade of 2004-2013, among the 220 papers on interpreting teaching among the total 597 articles, accounting for $37 \%$ of the total, there are unfortunately only 1 article on translation trainers, and it centers on the teachers' reflection in TOT (Wang Qian, Liu Heping, 2015). Some scholars analyze the articles of the CNKI and other journal networks and finds out that in the past few years, the interpretation profession has become increasingly concerned with translation professionalism and translation education, or professional translation education $(\mathrm{Mu}$ Lei, 2007; Tao Youlan, 2007; Liu Heping, 2016). However, related researches mostly focus on macro-strategy research or macro-research on translator training. There is no systematic research on translation trainers, especially interpreting trainers. And there are even less studies in combination with the emerging teacher education theory, such as the "post-method", which is a kind of teachers' education theory.

In fact, the self-development of translation teachers has attracted wide attention from translation scholars as early as 10 years ago. On April 21st, 2007, at the "National First Roundtable Conference on Translation Professional Construction in China" held at Fudan University, the selfdevelopment of translation teachers has aroused hot discussion. Some scholars pointed out that translator teachers must not only have the desire for self-development, but also have a clear understanding of translation studies, translation teaching, and pedagogy. In a word, they must also have a clear understanding of their strengths and weaknesses, so as to understand and adapt to their working environment, and work out their developmental goals and finally realize their self-development (Mu Lei, 2007). At the same meeting, Wu Qing specifically emphasized that professional translation teachers should have certain teaching experience and clear research interests and awareness to ensure the organic combination of theory and practice (Tao Youlan, 2007). Ten years later, however, according to the literature review, it is found out that the research on autonomous development of interpreters is still insufficient, and the study on the autonomous development of interpreter teachers by referring to the newly teacher education theory, such as postmethod is even rare. 


\section{RESEARCH BACKGROUND}

\section{A. Pervious Studies on Interpreting Education}

Professionalization of interpreting education has recently drawn wide attention. Some scholars hold that professionalization refers to the standardization, regulation, and institutionalization of a profession, including occupational behavioral norms, professional literacy, and the professional skills that should be followed, that is, a professional should say and do suitably at the right time, in the right place and with appropriate ways (Jiang Xun, 2009). Some scholars point out that professionalization of translation expands the field of translation, innovates the concept of translation, and points out the new goals for translation studies and personnel training (Huang Dexian, Du Xiaojun, 2010). To sum up, professionalization consists of the following three parts: professionalism, professional behavior, and professional skills and realization of professionalization in interpreting is a systematic project involving training, qualification certification, professional organization, and continuous education (Bao Chuanyun, 2007).

As to the nature and characteristics of interpretation education in the era of professionalization, some scholars have pointed out that the essence of interpretation education lies in the way to train professional interpreters according to the needs of the society in a purposeful, systematic way" It is not difficult to see that market factors play a large role in professional interpreting education, but its core is still the cultivation of "people" (Liu Heping, 2016: 47). The cultivation of professional interpreters is inseparable from professional teachers, therefore the sustainable development of interpretation teachers is crucial. Frans De Laet ever proposes that teachers are the guarantee for the implementation of the curriculum and the professionalization of translation ( $\mathrm{Wu}$ You, Li Wei, 2016). In conjunction with the rapid development of modern technology, some scholars have suggested that interpretation education should adhere to the approach of professionalism. Talent training programs and curriculum systems should reflect regional characteristics and school characteristics, and achieve dislocation development (Liu Heping, Lei Zhonghua, 2017).

\section{B. Interpreters' Professional Development}

It is pointed out that teachers' education is not just the sum of "teacher" and "education" (Kumaravadivelu, 2012). In another word, teacher education is not a problem of $1+1=2$, but a problem of $1+1>2$ or even $1+1>3$. In recent years, with the development of the translation profession and the advancement of translation professionalization, the training of translators has received increasing attention. It is believed that professionalized teaching staff guarantees the quality in training professional translators (Chai Mingjiong, 2010). While the translation community has reached consensus on the need for training of translators. In this context, it is particularly important for interpreting teachers to explore sustainable and autonomous professional development on the basis of teacher training.
With the attention paid to interpreting teachers' professional development, there still exist some problems. According to some researchers, the problems related to teachers' development cover the following aspects, such as there are shortage of teachers in interpreting, uneven teachers' proficiency, unvaried methods of teacher training, and weak sustainable development of teachers. To sum up, teaching capacity, practical ability, and research capacity of interpreting teaching staff need to be strengthened. According to the findings of some research, currently there are two main sources of translation teachers: one is to employ professional translators who have practical experience, and the other is that teachers who originally engaged in foreign language teaching are diverted to teachers of translation. The former is a more common practice in professional translation teaching at the graduate level, while the latter is more common in undergraduate translation teaching, especially in the interpretation teaching. However, it is unrealistic for all professional translators who have practical experience to be employed to teach translation (Chai Mingjiong, 2010). In this context, the following questions deserve consideration, such as how to improve the professional ability, teaching ability, and research ability of existing interpretation teachers? How to realize their sustainable professional development? This is not only an urgent task for the current interpreter education sector, but also a problem that this study will focus on.

A qualified professional teaching staff is the key to professional translation education. Some scholars believe that by introducing short-term course teachers from the translation professional team could help practitioners to bring first-hand translation experience to class and students, while by bringing the translation teacher to the translation workplace to practice translation is also a helpful way to develop interpreting teachers' professional proficiency (Liu Heping, 2007). Idealized professional translation teachers should be those who have long been engaged in professional translation or professional translators, those who have both professional competence and teaching ability. While the teaching staff should combine international and domestic interpreters, academicians and teachers who could be full-time or part-time (Chai Mingjiong, 2010). At the 11th National Interpretation Conference in 2016, Prof. Liu Heping, Chai Mingjiong and other experts once again emphasized the importance of sustainable development of interpreting teachers. In this context, this study adopts the "post-method" teacher education philosophy to explore the paths and methods for the autonomous development of professional interpreting teachers. 


\section{ENLIGHTENMENT OF THE "POST MeTHOD" ON INTERPRETING TRAINERS' AUTONOMOUS DEVELOPMENT}

Since there is no best teaching method in the world, why should we search one in vain? Therefore, we should try to find alternatives to the particular methods, or to find the suitable teaching method instead of a so-called best one. According to Kumaravadivelu who formally proposed the concept of postmethod, he states that "The postmethod condition is a state of affairs that compels us to refigure the relationship between the theorizers and the practitioners of method" (Kumaravadivelu, 1994: 28). By proposing the concept of postmethod, the author hopes that "It can empower teachers with the knowledge, skill, attitude, and autonomy necessary to devise for themselves a systematic, coherent, and relevant alternative to method that is informed by principled pragmatism (Kumaravadivelu, 1994: 44). This means that the teacher could autonomously recognizes that the teacher basic abilities include knowing how to teach and how to act autonomously under special conditions. In addition, the postmethod follows the principle of pragmatism and proposes that teachers have the ability to organize and manage their own classrooms (Kumaravadivelu, 2012).

To conclude, the concept proposed by postmethod, especially the idea on empowerment of teachers and learners, has great enlightenment on interpreting teachers' autonomous development. To be specific, the postmethod advocates that teachers should base themselves on the social environment they are in and construct their own teaching methods and teaching modes following a way of bottom up exploration. It also advocates that teachers promote themselves through teaching activities, especially through conducting action research in the process of teaching. All the above proposals related to postmethod could provide interpreting teachers new insight on their teaching and professional development. Therefore, the author attempts to adopt postmethod to explore interpreting teachers' autonomous development backgrounded on the current social, economic and cultural situation of China, hopefully enhancing interpreting teachers' autonomous development and pushing forward relevant teacher education reform.

\section{INTERPRETATION OF TRAINERS' AUTONOMOUS DEVELOPMENT MODE}

\section{A. Lifelong Learning Philosophy}

By analyzing studies on interpreting teaching at home and abroad, some scholar put forward a concept of Practeasearcher (practitioner + teacher + researcher), which integrates interpreting practice, interpreting theory, and interpreting teaching(Lu Xinchao, 2016). Specifically speaking, it refers to the fact that interpreting teachers should be professional translators having received professional training and rich in interpreting practice, so as to conduct interpreting practice, teaching and research in an integrated way. This concept embodies the basic ability framework for interpreting teachers. Based on this concept of Practeasearcher proposed by $\mathrm{Lu}$ Xinchao (2016), the author attempts to further explore the path and ways for interpreting teachers autonomous development.

In the perspective of postmethod, interpreting trainers could upgrade their theoretical proficiency through formal teacher education or training, by using real interpreting projects to maintain or improve their practical interpreting abilities, or by improving their teaching and theoretical abilities in the process of teaching practice. On one hand, interpreting teachers build interpreting teaching theory in a bottom-up way through teaching practice. On the other hand, interpreting teachers could apply the interpreting theory to teaching practice and further construct a new teaching theory. By doing this, an open, progressive cycle from theory to practice and from practice to theory is ultimately achieved.

With regards to the progressive and advancing characteristics of interpreting activities, the interpreter's lifelong development philosophy includes three layers of meaning. First of all, to form a life-long learning habit, including learning interpreting, teaching and other related theories and skills; Second, to conduct sustainable learning by conducting interpreting practice, updating relevant professional knowledge and enlarging their encyclopedic knowledge; Finally, to put theory into practice by testing existing translation and teaching theory and building new theories based on interpreting and teaching practice. Through the above three steps, hopefully interpreting trainers could achieve their autonomous development.

\section{B. Interpreters' Competence Framework}

Some scholars have suggested that modern foreign language teachers should at least possess the following two abilities: one is the ability of autonomous development, namely self-awareness, self-evaluation, self-renewal, self-challenge, self-reflection ability, and autonomous learning; the second is the ability to help others develop, including the ability to enlighten thinking, stimulate action, guide methods and guide practice. That is, the teachers themselves not only understand some knowledge, but can, will, and are willing to help others understand it. Only in this way can they highlight their professional competence (Xia Jimei, 2006). It can be seen that teachers' autonomous development ability is the precondition for the sustainable career development of teachers, while action is the key to realize it. 
Based on the current characteristics of the development of interpreting teachers, the author constructs a development framework of the interpreting teachers' competence and put forward a specific implementation path, as shown in Figure 1.

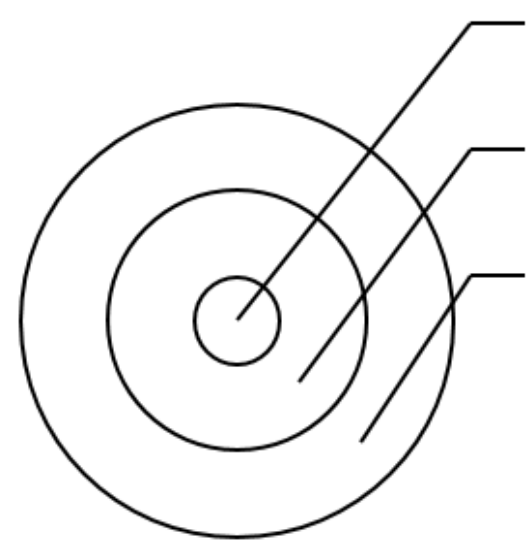

\section{Interpreting Teaching \\ (Action Research)}

Interpreting Practice

(Research Projects)

Theoretical Competence

(Life-long Learning)

Fig. 1. Interpreting trainers' competence framework

The interpreting trainers' competence framework consists of three parts, and their relationship is as follows: The inner ring is interpretation teaching, the central ring is the interpreting practice, and the outer ring is the interpreting theory, including both the interpretation theory and the teaching theory. In addition to mastering interpreting theories and teaching theories, current interpreters must also master information capabilities and intelligent learning methods. In addition, the action research is the main method of interpretation teaching, the interpretation project acts as the carrier of interpreting practice, while lifelong learning is the guarantee of improving the theoretical competence.

The interpreting teachers' competence framework has the following characteristics:

First of all, interpretation teaching is the core of the development of interpreting teachers, and is both the starting point and destination of the development of interpreting teaching interpreters. On one hand, the interpretation teaching is a platform for their autonomous development, and on the other hand, it is also the place where the interpreting teachers examine of the efficiency of their professional development. For example, through carrying out the interpreting action research, the interpreting teachers construct their own interpreting teaching theory suitable for the specific class and individual learners so as to find problems existing in interpreting teaching, propose countermeasures, and help improve the teaching efficiency.

Secondly, the interpreting practice ability is in the middle of the development of the interpreter teacher, connecting the interpretation teaching and interpretation theory. Interpreting ability is a prerequisite for qualified interpreting teachers, and it is also an indispensable link for their development. Practical ability is the premise for effective interpreting teaching and the means of improvement is by doing real and simulated interpreting projects.

Thirdly, improving the quality of interpreting theory and teaching theory is the guarantee for the independent development of interpreters. The promotion of theoretical competence depends on the lifelong learning ability of interpreting teachers. Only when interpreting teachers are highly sensitive to various relevant theories and have the ability to learn for life, can they update their theoretical knowledge and keep up with the times. The post-method concept advocates that teachers build their own classroom teaching theory suitable for specific students and classrooms, and use their guidance in their own classroom teaching, so as to achieve mutual promotion of theory and practice, and ultimately enhance the teachers' theoretical quality and improve teaching effectiveness. In addition, interpreting teachers also need to understand some necessary cross-border theories and knowledge literacy, such as cognitive science, psychology, pedagogy, learning science, sociology, philosophy, information technology and other interdisciplinary knowledge and capabilities.

Finally, independent development of interpreters does not exclude all types of teacher development training. The interpreting teachers with self-development consciousness and ability know how to participate in teacher training selectively, and know how to integrate top-down training and selfdevelopment from the bottom up, thereby maximizing selfdevelopment and improving the level of interpreting theory and practical ability.

\section{Interpretation Trainers' Evaluation Framework}

In order to effectively evaluate the interpreting trainers' autonomous development ability, the author proposes to construct an independent development assessment framework, as shown in Figure 2. The framework includes several aspects such as teacher self-assessment, school evaluation, social assessment, and market evaluation. Among them, the self evaluation of interpreting teachers is the core, acting both as the starting point and destination of independent development assessment, which can help the interpreter teachers to find out the problems encountered in the process of self development so as to propose solutions. 


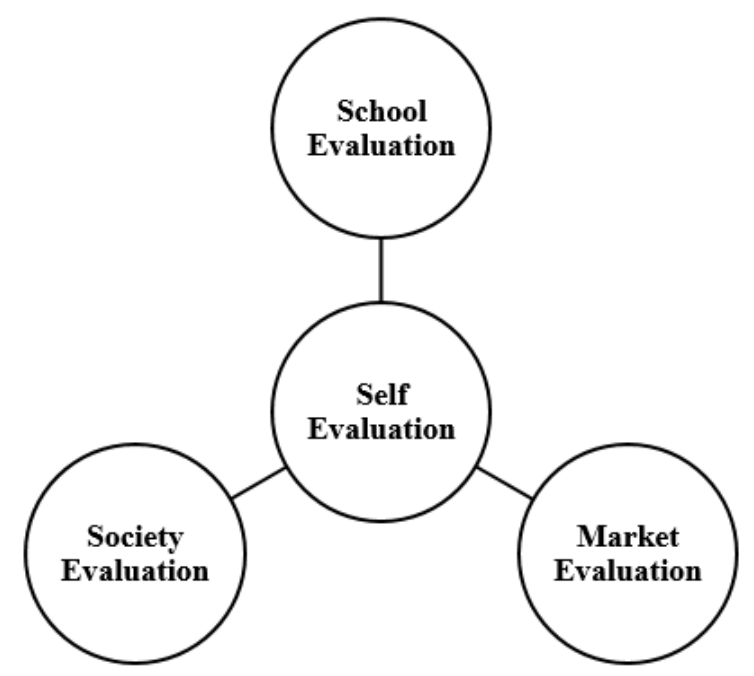

Fig. 2. Interpretation trainers' Evaluation Framework

The relationship between different parts in the framework is as follows: first, in the process of self-evaluation, interpreting teachers can achieve objective and comprehensive selfassessment through the formulation, implementation, evaluation, and self-reflection; secondly, the interpreting teachers are evaluated by all parties in the interpreting practice. In the process of self development assessment, interpreting teachers should give full play to their enthusiasm and initiative of self-assessment and conduct introspective self-assessment. It is necessary to mention that assessment is not the end of teacher development, but the starting point and motivation of teachers' self-development. Efficient teacher self-assessment should be based on the self-assessment of teachers, and be inclusive of others, especially the third-party evaluation from their colleague and even the market. Only in this way can the purpose of the assessment be truly achieved. To draw a summary, trainers' self assessment can promote their sustainable professional development, and the third party or external assessment can drive their motivation in selfdevelopment.

\section{CONCLUSION}

This study combines the development status of interpreting teachers under the background of professionalism and draws on the post-method teacher education philosophy to explore the path of self development of interpreting trainers, the lifelong development awareness, the competence framework, and assessment framework are respectively discussed. The author holds that the concept of strengthening the lifelong development of interpreting trainers is the premise to realize their self development; the construction of the interpreting teachers' competence framework is the guarantee for realizing their self development. The interpreter teacher's selfdevelopment assessment mechanism is not only an effective means to detect the independent development of interpreting teachers, but also a driving force for the sustainable development of interpreting teachers. However, while recognizing the importance of self development of interpreting teachers, the role of various types of interpreter teacher training should not be ignored. It is proposed that training of trainers based on self development will be more effective and more targeted, and can better meet the individual needs of individual trainers. Therefore, exploring the effective integration of interpreting trainers' training and their self-development will be the direction of future studies on interpreting trainers' sustainable development.

\section{ACKNOWLEDGMENT}

Funded Project: The paper was funded by the 2017 Philosophy and Social Sciences Project of Zhejiang Province (Project number: 17NDJC292YB), 2018 Philosophy and Social Sciences Project of Zhejiang Province (Project number: 18NDJC284YB), the Postgraduate Research and Innovation Fund of Sichuan University (Project number: 2012017yjsy134) and the 2017 Higher Education Research Project of Zhejiang Wanli University.

About the author: Wang Honglin (1978- ), Phd Candidate of Sichuan University, Associate professor of Zhejiang Wanli University. Research areas: Applied linguistics, translation and interpreting studiesAddress: Wangjiang campus of Sichuan University, No.24 South Section 1, Yihuan Road, Chengdu, China 610065.Email: fycarol61@163.com.Mobile: 13486644420 


\section{REFERENCES}

[1] Kumaravadivelu, B. The postmethod condition: (E) merging strategies for second/ foreign.

[2] Language teaching [J]. TESOL Quarterly, 1994, 28(1), 2748.Kumaravadivelu, B. Language teacher education for a global society [M]. New York, NY:

[3] Routledge, 2012.Bao Chuanyun. On Training of Transltion Trainers: The key to translation teaching [J]. (In Chinese)

[4] Translators Journal, 2009(2): 45-47. Chai Mingjiong. Reflection on Construction of Professional Translation Teaching: Current Studies, Problems and Suggestions [J]. Chinese Translators Journal, 2010(1): 5456. (In Chinese)

[5] Hua Liang. Research on the Professional Development of Teachers with Master of Translation: A Survey Based on Teachers of Interpretation[J]. Theory and Practice of Education, 2016(6): 37-39. (In Chinese)

[6] Huang Dexian, Du Xiaojun. Influence of Translation Professionalization on Research of Translation[J]. Shanghai Journal of Translators, 2010(1): 73-77. (In Chinese)

[7] Jiang Xun. Professionalization[M]. Beijing: Economics and Management Press, 2009. (In Chinese)

[8] Liu Heping. Ten Years of China's Interpreting Education: Reflection and Visions[J]. Chinese Translators Journal, 2016(3): 46-52. (In Chinese)

[9] Liu Heping, Lei Zhonghua. Reflection on Interpreting Professioniazation + Profession: Challenges and Suggestions[J]. Chinese Translators Journal, 2017(4): 77-83. (In Chinese)

[10] Lu Xinchao. Chinese Interpretation Teaching: Problems and Solutions[J]. Shanghai Journal of Translators, 2016(4): 60-67. (In Chinese)

[11] Mu Lei. Professionalization of Translation and Professional Translation Education [J]. Chinese Translators Journal, 2012(4): 13-14. (In Chinese)

[12] Tao Youlan. Translation Teachers Development in the New Situation[J]. Foreign Language World, 2007(3): 30-34. (In Chinese)

[13] Wang Qian, Liu Heping. New Developments of Interpreting Studies in China (2004-2013) [J]. Shanghai Journal of Translators, 2015(1): 7783. (In Chinese)

[14] Wu Xiao, Li Keke. An Interview with Frans De Laet [J]. Shanghai Journal of Translators, 2016(5): 77-83. (In Chinese)

[15] Xia Jimei. A Literature Review of the Research on theForeign Language Teacher.

[16] Development [J]. Foreign Language of China, 2006(1): 62-65. (In Chinese) 